\title{
THE MISSION TO LEPERS IN-PATIENT UNIT OF THE KYUNGBUK UNIVERSITY HOSPITAL, TAEGU, KOREA \\ JAN. 1st-DEC. 31st, 1960 \\ G. K. WILSON, M.B., B.S.
}

On 5th December, 1959, Dr. Han of the Ministry of Health and Social Affairs of the Republic of Korea opened The Mission to Lepers In-patient Unit in the Kyungbuk University Hospital Compound.

The purpose of this 4-bed unit was to supplement the work of the out-patient clinics begun in 1957 by the Rev. C. M. and Mrs. Lloyd and Miss Grace Bennett, S.R.N., by providing more spedialised care of patients with lepra reactions and other complications. A further aim was to find out whether this would prove a satisfactory method of meeting this need; and as far as possible to assess how great the need might be.

The unit is part of the Government General Hospital with its attached Medical School and is thus in a most strategic position both medically and spiritually. The consultant services of all departments are available as well as the facilities of the operating theatre, the X-ray, clinical and surgical pathology, and pharmacy departments. The leprosy centre is, in fact, a Leprosy Department of the General Hospital, and as such is treated like any other department.

Details of the work undertaken in this department during 1960 are as follows:

\section{Admission}

30 patients were admitted, two of whom were readmitted for other conditions than those treated on the first occasion. Ages ranged from 17 to 59 years.

\section{Sex}

Of the 32 admission 24 were male, 8 female.

\section{Classification}

$\begin{array}{lcll}\text { Indeterminate } & 2 & \text { Tuberculoid } & 10 \\ \text { Borderline } & 0 & \text { Lepromatous } & 20\end{array}$

\section{Bacillary Index}

19 patients were negative, of whom 7 were classified as lepromatous, 10 as tuberculoid and 2 indeterminate. 


\section{Source}

9 patients were admitted from the Taegu Clinic, 16 from the mobile clinics and 5 from leprosy colonies lacking facilities for the treatment indicated.

Duration of stay varied from 1 to 63 days. The average stay for reaction cases was 33 days; for those on whom operations were done for foot ulceration it was 36.1 days.

\section{Operations}

21 operations were performed. Two patients each had two operations; one had three (and a fourth in 1961).

\section{Conditions for which patients were admitted}

$\begin{array}{lccclccc}\text { Reaction } & \ldots & \ldots & 5 & \text { Injuries } \ldots & \ldots & \ldots & 2 \\ \text { Anaemia } & \ldots & \ldots & 1 & \text { Liver abscess } & \ldots & \ldots & 1 \\ \text { Neuritis } \ldots & \ldots & \ldots & 2 & \text { Amputation forearm } & \ldots & 1 \\ \text { Nephritis... } & \ldots & \ldots & 1 & \text { Incision finger } & \ldots & \ldots & 1 \\ \text { Foot ulceration } & \ldots & \ldots & 8 & \text { Hepatitis } \ldots & \ldots & \ldots & 1 \\ \text { Carcinoma } & \ldots & \ldots & 2 & \text { Ovarian cyst } & \ldots & \ldots & 1 \\ \text { Hydrocele } & \ldots & \ldots & 2 & \text { Cataract } \ldots & \ldots & \ldots & 4\end{array}$

$25 \%$ of admissions were for conditions other than those directly or indirectly due to leprosy.

The operations performed on the 30 patients admitted were for other conditions than leprosy:-

(1) Ovarian cystectomy.

(2) Halstead's Mastectomy for carcinoma of breast.

(3) Gastro-jejunostomy for inoperable carcinoma of the stomach.

(4) Hydrocele sac excision.

(5) Hydrocele sac excision with epididymectomy and orchidectomy.

(6) Herniorraphy.

(7) Laparotomy and drainage of liver abscess.

for complications of leprosy:-

(1) (2) (3) Curettage of sequestra in foot ulceration.

(4) Metatarsectomy of 5th digit.

(5) Amputation of 1 st and 2nd digits to the Navicular bone.

(6) Transverse mid-metatarsal amputation.

(7) Amputation of forearm for gangrene.

(8) Ulnar nerve sheath stripping fo neuritis.

(9) Eyebrow transplant.

(10 Secondary suture of wounds. 


\section{Ophthalmic operations:-}

Cataract operations on 4 patients.

\section{Results}

Reactions. Although general measures were tried at first, pyrexia did not respond until Stibophen was used. Including the patient who was admitted with anaemia, and who developed lepra reaction during his stay, haemoglobin values in 4 of the 6 patients were below $65 \%$, and gave poor response to iron therapy. 4 of the 6 patients were lepromatous.

Acute Neuritis. One of the two patients was discharged after five days, but continued to have intermittent neuritis. The other patient had relief from pain for 3 months following the nerve sheath stripping operation; later the pain was much less than before the operation.

Nephritis (Bright's disease Type II). There was a satisfactory initial response to treatment, albuminuria becoming minimal after 26 days. Albuminuria had disappeared after five months.

Foot ulceration. Six operations were done under spinal anaesthesia. One was cauterised and trimmed without an anaesthetic. In three the results have so far been satisfactory; in two the results are not yet known. One in a woman who was pregnant healed without operation.

In two patients the ulcers were over the lateral malleoli, a common site due to the Korean habit of sitting cross-legged and unprotected on a hard, and often very hot floor.

Carcinoma. The patient with carcinoma of the breast showed no signs of metastases 10 months later, when she was admitted for foot ulceration. The patient with the inoperable carcinoma of the stomach died a month after a gastro-jejunostomy.

Hydrocele. In both patients the results appear satisfactory. One patient had had a herniorraphy without release of symptoms, so the hydrocele sac was excised together with diseased epididymis and testis. This patient had eyebrow transplants done, and was in the ward for 63 days.

Injuries and burns. One patient was a girl of 17 with multiple burns on hands and legs. The other was a boy of 19 who had allowed a fellow-patient to remove not only the whole of his third finger, but also the metacarpal bone as well, the exposed wound being left to granulate. Secondary suture was performed to this and another smaller wound.

Liver Abscess. This patient was admitted from the Roman Catholic leprosy colony about 20 miles away. A laparotomy was done followed by drainage of the abscess. 
Amputation of the Forearm. This patient was admitted from the Roman Catholic colony. Gangrene had developed and amputation of the forearm was undertaken.

Incision of Finger. The patient came 200 miles with a cyanosed septic finger. Lateral incision relieved the pressure and the finger recovered.

Hepatitis. This patient had jaundice and diminished liver function, both of which returned to normal. He also developed psychotic disturbances so has been put on DPT.

Ovarian Cyst. Unfortunately there was such delay before the operation could be undertaken and the patient died under the anaesthetic.

Cataract. Extractions were performed on four patients. One was successful in the patient who developed an inoperable carcinoma of the stomach. Two cases have not returned since the operation. One was referred from a leprosy colony from which no further report has been received.

\section{Comments}

The four-bed unit has met the need for which it was planned; it has proved that patients will come for in-patient treatment and that this is a satisfactory way of meeting the need.

The total need is still difficult to assess; emergency treatment was needed for some patients whom we could not admit. At the end of the year there was a waiting list of 15 and only those in most urgent need could be admitted. Further the numbers attending the clinics are steadily increasing; in addition it is found that the worst sufferers concentrate in numerous small leprosy villages from which we needs must admit patients for special care and attention.

The growth of the out-patient clinics begun in March 1957 is shown in the following figures:-

\begin{tabular}{|c|c|c|c|}
\hline March 1958 & \multicolumn{3}{|c|}{ atients } \\
\hline March 1959 & 413 & , & \\
\hline March 1960 & 578 & , & , \\
\hline Nov. 1960 & 660 & , & , \\
\hline
\end{tabular}

\section{Conclusions}

The co-operation of the University Hospital has made for success in this experiment. It is hoped that this co-operation may continue and make possible an expansion of the unit to 15-20 beds to help meet the need not only for the emergency treatment of out-patients, but also for reconstructive and plastic surgery. This work has not as yet been undertaken, but its importance is realised especially for those patients who return home after attending clinics. 
The value of the centre for the training of medical students is also appreciated, as it is possible for them to learn to treat leprosy as another disease, and leprosy patients as any other patients but perhaps even more in need of personal interest, care and help. 